\title{
Benchmarking Sustainability on an Industrial Case Within Industry 4.0 Paradigm: Advantages of Involving Exergetic Analysis in Life Cycle Thinking
}

\author{
Valeria Selicati*, Nicola Cardinale \\ Department of European and Mediterranean Cultures (DICEM), University of Basilicata, Via Lanera, 20-75100 Matera (MT), \\ Italy
}

Corresponding Author Email: valeria.selicati@unibas.it

https://doi.org/10.18280/ti-ijes.642-418

Received: 24 March 2020

Accepted: 19 May 2020

\section{Keywords:}

exergy, industry 4.0, life cycle assessment, smart sustainable manufacturing

\begin{abstract}
With the constant increase in energy costs and their impacts on environmental policies, optimizing production and reducing operating costs is considered a critical tactic for companies to remain globally competitive. In the height of the Industry 4.0 era, the need to digitize and automate manufacturing processes emerges as another predominant goal. The difficulty lies in understanding how thermodynamic laws can enhance energy efficiency and support for the strategies to approach the transformation into a smart factory. To this end, LCA is the most used tool that helps to measure the consumption of resources throughout the entire life cycle of the process. The Exergetic Analysis (EA) adds information on the efficiency.

The goal of this work is to show that hybridizing LCA with EA brings significant advantages: it makes the outcomes of the assessment more objective and it helps to develop retrofitting solution, thus enabling the process to automatically prevent any machine failures. In line with the Industry 4.0, any company would be able to select appropriate sensing infrastructure to enhance its monitoring and management system and redesign it, making it smarter.

An illustrative case study on an Italian SME's manufacturing process will be addressed in this paper.
\end{abstract}

\section{INTRODUCTION}

At the height of the Industry 4.0 era, the need to digitize and optimize manufacturing processes, driving to production efficiency and lower operating costs, is critical for enterprises to stay globally competitive. Currently, Industry 4.0 (I4.0 from now on) is highlighting the need to operate under environmental restrictions in order to be sustainability oriented.

The Key Enabling Technologies (KETs) of I4.0 [1], and the improvements that they foster, have an effect on raw materials flows, resources, goods, energy, pollution, properties and knowledge which, as a result, have a favorable or negative influence on environmental sustainability.

Sustainable manufacturing has been received awareness in terms of process control, energy analysis and low carbon emissions, especially within the I4.0 paradigm.

Wide knowledge about all the data related to materials, energy, machinery and auxiliary equipment is mandatory in order to optimize overall process performances.

In the light of these innovating technologies, it is necessary to understand which methodologies are best suited to evaluate both qualitatively and quantitatively their sustainability and the one of the whole processes.

To this end, LCA is the most used tool that helps to quantify the consumption of resources flows throughout the entire life cycle of the process and its potential harm to the environment.
The Exergetic Analysis (EA) adds information on the quality of the process in terms of efficiency.

The goal of this work is to show that hybridizing LCA with EA brings significant advantages: it makes the outcomes of the assessment more objective and it helps to develop retrofitting solution, thus enabling the process to automatically prevent any machine failures. In line with the Industry 4.0, any company would be able to select appropriate sensing infrastructure to enhance its monitoring and management system and redesign it, making it smarter.

The hybrid implementation of these two methods has proven to be a valuable tool for understanding process management alternatives and for optimizing and innovating production process technologies.

All these statements are endorsed by the assortment of hybrid methods existing in literature, which differ from each other for the distinct levels of hybridization between EA and LCA and for the variety of input and output flows that they consider.

The rest of this paper is organized as follows. The I4.0 paradigm and the role of sustainability related to it are described in Section 2. As KETs of I4.0 paradigm, the methodologies for dealing with manufacturing sustainability are widely reviewed in Section 3. A real industrial case is presented in Section 4, on which LCA, EA and hybrid EALCA are conducted and discussed, followed by the concluding remarks and further developments in Section 5. 


\section{SUSTAINABILITY RELATED TO INDUSTRY 4.0}

Industry 4.0 was introduced in 2011 by German Government to indicate a set of technological changes in manufacturing systems by means of automations and ICT (Information and Communication Technologies), including Cyber-Physical Systems, Internet of Things, Simulation and Modelling, Big Data Analytics, Augmented Reality, Additive Manufacturing, Robotics, Cloud Computing and now also Blockchain. It aims to help incorporate and merge autonomous devices, human beings, physical objects and processes through operational stages in order to create different forms of digital data, functional and high agility value chains during the whole life cycle of a product, process or activity [2].

It is possible to list a set of key-features of I4.0 paradigm that lead to smartness [3]: a) automation, b) decentralization, c) real-time data acquisition, processing and communication, d) virtualization, e) modularity, f) flexibility, g) agility, h) efficiency, i) interoperability, j) prediction, and j) customization.

It is evident that the guiding principles of I4.0 were not initially focused on providing alternatives to the ecological problems posed by manufacturing, but on improving efficiency and profitability. Today, I4.0 is supported in every field, not only manufacturing as logistics, construction, transportation, medicine and surgery, food production, home automation and so on, even in our daily life with smartphones and watches.

If on one hand any company drops its basis of existence without economic profitability [4], very soon the companies have come to understand the value and the competitive advantages of proactive environmental practices. The related advantages span a broad spectrum [5], such as the reduction of pollution and environmental risks, and the enhancement in financial performance due to openings in new foreign markets. In fact, an eco-friendly organization would be able to obtain environmental certification with the associated boost in prestige. Industry 4.0 would be a step forward for more competitive manufacturing value development. In current literature, this phase is mainly defined as a commitment to the environmental aspect of sustainability. The distribution of services, i.e. goods, supplies, electricity and power, may be made more effective on the basis of insightful cross-linked value creating modules [6].

\section{METHODOLOGIES}

To understand how LCA and EA can be related to sustainability within I4.0 paradigm, let us briefly introduce the key enabling technologies of Industry 4.0 [7]: Internet of Things (IoT) enables companies to connect multiple devices, which are logistically remote, using sensors and microprocessors powered by software systems capable of transmitting information across the network. Big Data Analytics refers to a new generation of technologies and architectures that enable organizations to economically extract value through discovering, capturing and analyzing very large volumes of a wide variety of data. It leads to the Artificial Intelligence (AI). Cybersecurity and Blockchain protocols needed by companies in terms of knowledge sharing and data privacy to better protect a device or a device collection. Blockchain is permanent, decentralized and redefines confidence because it allows open, safe, efficient and prompt public or private solutions. Augmented reality (AR) to the idea of utilizing specific viewers to obtain extra details about the product simply by framing it. Robotics and Advanced Manufacturing Solutions because robots are actual interactive devices capable of sharing knowledge with other devices and human beings, continuing to remain autonomous while configuring the trajectories according to the needs of the output flow. Additive manufacturing, a technology which, beginning with the digital CAD drawing of the product to be made, is capable of printing it by adding material. The nozzle can melt thin layers of powder and add one layer of material, either plastic or metal, on top of another, in order to create any shape. Simulation and modelling techniques would be required to exploit real-time data to replicate the physical environment in a simulated model that may involve computers, goods and humans.

Considering that, among KETs, there are big data analytics and modeling techniques [8], we focus now on the modelbased approach, that is, the study of the process through physical (in our case, thermodynamic) models. The physicalthermodynamic models addressed in this work are Life Cycle Assessment and Exergy Analysis.

\subsection{Life cycle assessment}

The Life Cycle Assessment (LCA), regulated by ISO 14040 and ISO 14044, is a widespread analytical tool used to measure and analyze environmental flows through the entire life cycle of a product process or activity [9, 10]. The modern structure of the LCA proposed by ISO 14040 series consists of four main phases, and a last one, about the construction of an environmental indicator, as shown in Figure 1.

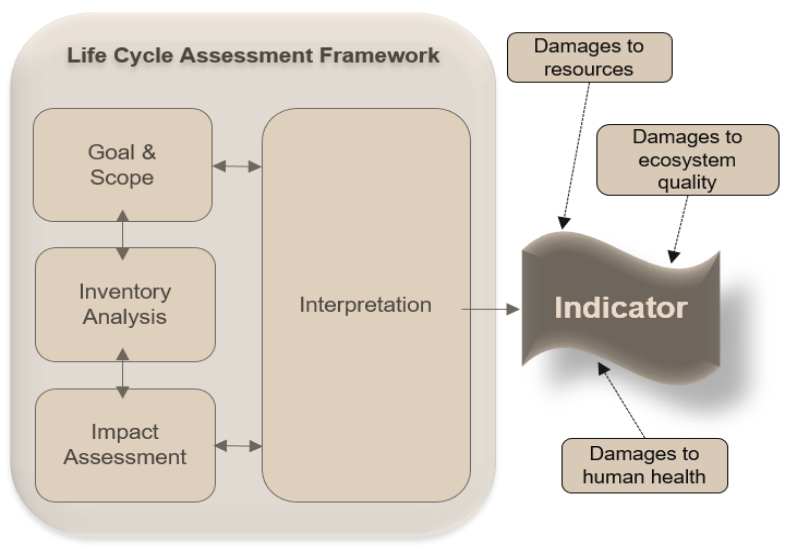

Figure 1. LCA framework according to ISO 14040

An in-depth overview of the LCA methodology and its regulation has been already developed by the authors in a previous work. In that case, the analysis was applied to the construction sector [11].

LCA is known to be an eco-design tool par excellence because it enables each aspect of a good or service to be analyzed in depth, exploring the nature of the whole life cycle. It facilitates the recognition of the most affecting systems and stages and also gives a good picture of the issues that need to be resolved by the action targets.

This method is based on linear equations because it sums up quantities, see section 4.1 for an example.

The most trivial part of an LCA is indeed the inventory phase (LCIA). The life cycle inventory analysis phase consists of determining both inputs (materials and energy resources) 
and outputs (emissions and environmental waste) to and from the product or process under study. Data collection may be especially time-intensive and resource-intensive, as it may cover both upstream processes (resource acquisition, processing and transport) as well as downstream processes (product consumption and disposal). To facilitate data collection as well as the full application of the LCA, the upstream and downstream data could be found in opensource or payment databases, such as Ecoinvent, USLCI and so on. Software such as SimaPro or Gabi or OpenLCA helps users to conduct the evaluation in a more direct and intuitive way [12]. Obviously, they do require databases to operate and are thus not open to any practitioner.

\subsection{Exergy analysis}

Exergy is defined as "maximum theoretical useful work obtainable as the system is brought into complete thermodynamic equilibrium with the thermodynamic environment while the system interacts with this environment only" [13]. When a system is in perfect equilibrium with its reference environment (i.e. no temperature gradients are present), there is no exergy at all. More the exergy is created, more the system is far from its equilibrium.

EA provides a perfect frame to evaluate efficiency in a single metric, which is a sort of measure of reversibility of the processes, reducing the interpretation issues inherent the LCA.

Exergy is conserved only in reversible processes (ideal processes, as it is Carnot cycle). In real processes, which are irreversible, a quantity of exergy is always destructed.

To this aim, the two ratios below represent a good interpretation of process performance.

- General exergy efficiency:

$$
\eta_{g}=\frac{\sum \dot{E x^{\text {product }}}}{\sum \dot{E} x^{\text {input }}}
$$

- $\quad$ Net use efficiency:

$$
\eta_{n}=\frac{\sum E x^{\text {output }}}{\sum E x^{\text {input }}}
$$

In real processes, these ratios are always $<1$. The distinction between $\dot{E x}^{\text {product }}$ and $\dot{E x}^{\text {output }}$ is in the output flows taken into account in the sum: 'product' implies just the flows involved in the processing of the required performance; 'output' is the total amount of outlet flows (productions and losses) involved in the process or activity under analysis.

\subsection{Hybrid/Coupled EA-LCA}

While classical LCA tools have a major emphasis on emissions, EA is much more efficiency oriented [14]. Although the time period evaluated during the LCA is larger than that seen during an EA, all approaches are time dependent. Both during LCA and EA, it is important to establish a context of the analysis in which system boundary is named in LCA and the definition of the reference environment corresponds in EA [15]. Both LCA and EA consist of mass and energy balances, but LCA may not provide a standard metric, in fact several authors consider the Life Cycle a multidimensional evaluation approach [15], while EA has a single metric and this contributes to greater comparability and understanding.
Based on the literature, there are positive opinions on the utility of Exergy coupled with LCA as a metric of sustainability, as they are complementary tools $[16,17]$.

The integration of EA and LCA is thought to be possible to model a monitoring strategy which is a fundamental precondition for the implementation of Industry 4.0 technologies.

Hybridization may be achieved in many forms. For example, the two analyzes may be conducted independently and the outcomes of one and the other can ultimately be merged to give a more comprehensive image of the process or product being evaluated. Another way could be splitting EA into unitprocesses, each of which assesses a phase of the life cycle. There is not yet a pure hybrid model under which there is just an equation or algorithm based on the principles of the LCA, and those of the EA.

These assertions are supported by the number of hybrid approaches in the literature, which vary from one another in terms of the distinct degrees of hybridization between EA and LCA and the diversity of input and output flows that are inventoried. Far from describing each method as it is not the core of this work, some among the most applicants in the literature are Exergetic Life Cycle Assessment (ELCA) [18], Cumulative Exergy Demand (CExD) [19], and Exergoenvironmental Analysis [20].

\section{CASE STUDY}

The attention is now focused on a real industrial case of an Italian SME that produces all the small accessories for aluminum window and door frames.

The process under analysis is the window handle, as shown in Figure 2, composed by an aluminum knob, a case, covercase and a spindle in zamak, a bushing and a spacer in delrin and other auxiliary components as metallic screws and springs.

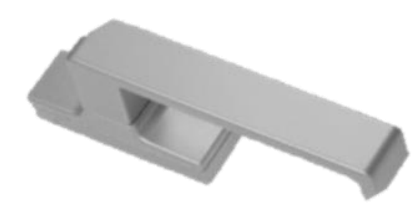

Figure 2. Window handle as industrial case study.

The goal and scope of this case study is to carry out a sustainability evaluation by LCA, EA and hybrid EA-LCA.

The following analysis is carried out with the same starting assumptions, saying, same functional unit, same system boundaries and same reference flows.

The functional unit, consistent with the goal and scope, is one piece of finished product which, in our case, corresponds to a single window handle. The functional unit provides a structure for the standardization (in a computational sense) of input and output data on the basis of which the performance of the analyzed process may be defined.

The system boundaries have been chosen according to the goal and scope.

For the specification of reference flows, the process is shown as a basic series of operations consisting of the description of its primary unit-function (i.e. subprocesses), its cycle times, and the efficient classification of its primary and 
secondary elements to be included in the analysis, as well as upstream and downstream processes.

\subsection{Life cycle assessment}

LCA's environmental analysis provides details on resource use, electricity use, carbon emissions over the product life cycle and future environmental effects in terms of $\mathrm{kgCO}_{2 \text { eq }}$. Impact category for the Global Warming Potential predictor

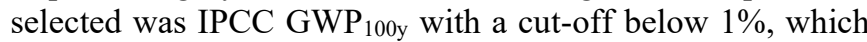
indicates that all subprocesses or components that contribute less than $1 \%$ to overall consumption are neglected in the final results. The program selected to do this LCA analysis is SimaPro v.9. This is a comprehensive IT tool which requires a number of databases, including the categories needed to describe the life cycle; in fact, they are classified and listed in each database: products, procedures, energy and transport systems, recycle methods and waste management. The database used is Ecoinvent v.3.

In Table 1 the results are shown in matrix form, in order to link each environmental impacts of the components of the handle to those related to each sub-process.

The following Figure 3 illustrates the overall impacts of one handle. The evaluation of the impacts for the GWP reported a total value of $3.2580 \mathrm{kgCO}_{2 \text { eq }}$ per piece on one year. The most affected component is the knob, of which die cast aluminum sub-process is connected as the most impacting. This implies that the goal for optimization is to focus on aluminum die-as a priority sub-process.

Table 1. LCA impact assessment by IPCC-GWP100y all expressed in $\mathrm{kgCO}_{2 \mathrm{eq}}$

\begin{tabular}{|c|c|c|c|c|c|c|c|c|}
\hline & Die casting Zamak & $\begin{array}{l}\text { Die casting } \\
\text { Aluminum }\end{array}$ & $\begin{array}{c}\text { Plastic } \\
\text { molding }\end{array}$ & $\begin{array}{c}\text { Vibro- } \\
\text { tumbling }\end{array}$ & $\begin{array}{c}\text { Drilling and } \\
\text { threading }\end{array}$ & Painting & Assembly & Total \\
\hline Bushing & & & 0.0150 & & & & & 0.0150 \\
\hline Case & 0.6030 & & & 0.0030 & & 0.0043 & & 0.6103 \\
\hline Cover-case & 0.3620 & & & 0.0010 & & 0.0056 & & 0.3686 \\
\hline Knob & & 1.9842 & & & 0.0074 & 0.0134 & & 2.0050 \\
\hline Spindle & 0.1524 & & & 0.0006 & & & & 0.1530 \\
\hline Assembly & & & & & & & 0.1060 & 0.1060 \\
\hline Total & 1.1175 & 1.9842 & 0.0150 & 0.0045 & 0.0074 & 0.0233 & 0.1060 & 3.2580 \\
\hline
\end{tabular}

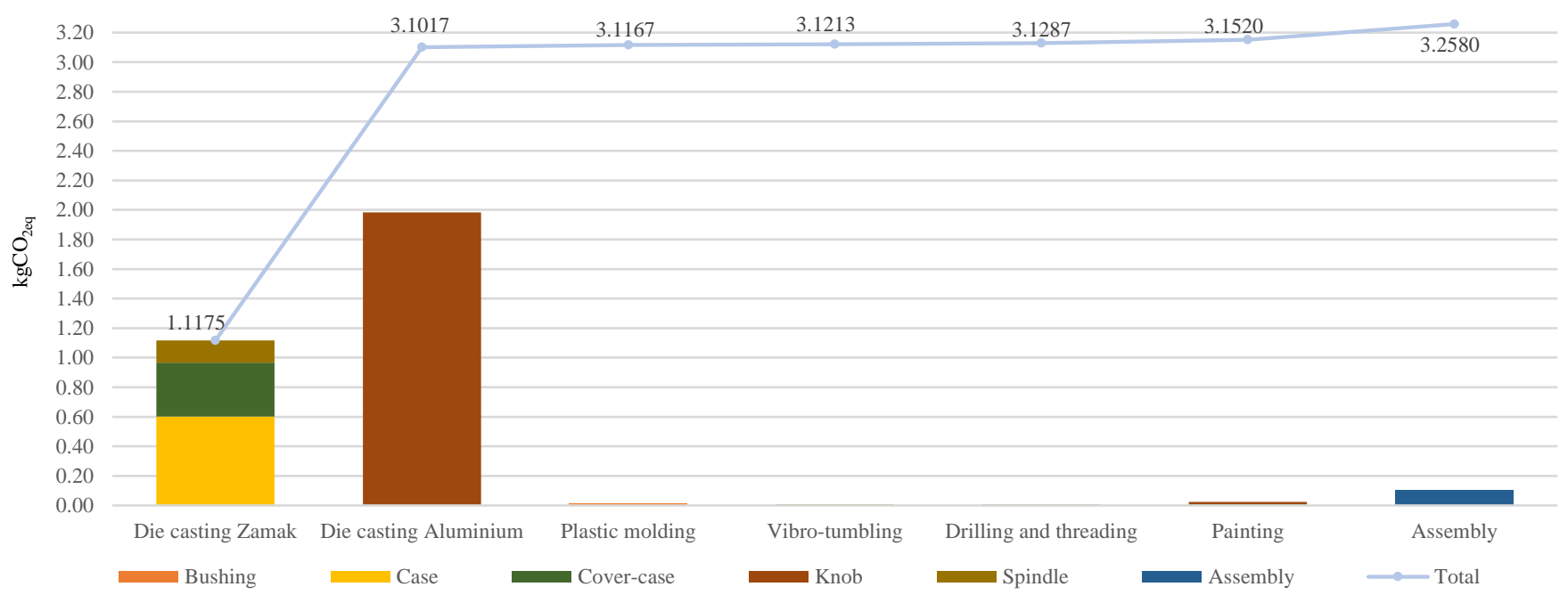

Figure 3. IPCC-GWP ${ }_{100 \mathrm{y}}$ : cumulative impact of each handle component related to the sub-process and vice-versa, in $\mathrm{kgCO}_{2 \mathrm{eq}}$.

\subsection{Exergy analysis}

Considering a generic sub-process in the overall manufacturing process of the handle, an example of inventoried input and output flows are shown in Figure 4.

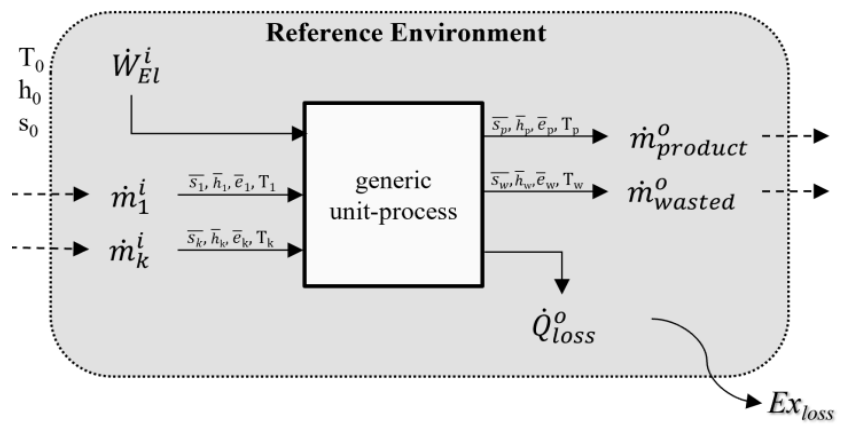

Figure 4. In/out flows of a generic thermodynamic system
Reference flows are uniquely identified in its balance equations. In our industrial case reference flows are:

Mass flow balance:

$$
\sum_{k} \dot{m}_{k}^{i}=\sum_{k} \dot{m}_{k}^{o}
$$

Energy flow balance:

$$
\begin{aligned}
\sum_{c} \dot{H}_{c}^{i}+\sum_{d} \dot{W}_{d}^{i} & +\sum_{p} \dot{Q}_{p}^{i} \\
& =\sum_{c} \dot{H}_{c}^{o}+\sum_{d} \dot{W}_{d}^{o}+\sum_{p} \dot{Q}_{p}^{o}
\end{aligned}
$$

The optimization criteria in the exergetic analysis is, in essence, the minimization of the term $\mathrm{Ex}_{\text {loss }}$ (exergetic loss is proportional to the entropy generated) and this latter is the 
cause of less-than-theoretical efficiency of the process.

Exergy flow balance:

$$
\begin{aligned}
\sum_{c} \dot{E} x_{c}^{i}+\sum_{d} \dot{W}_{d}^{i} & +\sum_{p}\left(1-\frac{T_{0}}{T_{e}}\right) \dot{Q}_{p}^{i} \\
& =\sum_{c} E x_{c}^{o}+\sum_{d} \dot{W}_{d}^{o} \\
& ++\sum_{p}\left(1-\frac{T_{0}}{T_{e}}\right) \dot{Q}_{p}^{o}+\boldsymbol{E} x_{\text {loss }}
\end{aligned}
$$

As can be seen from equation (5), temperature variations play a key role in the exergetic equilibrium.

The greater the disparity in temperatures in two transition phases, the greater the energy produced.

When an inventory of the data required to carry out the EA was made, it was observed that the temperatures of the mass flows in and out of the plant were not tracked at any operational phase of the processes. The only temperatures controlled were the environment temperature and the temperature of the furnaces. Insufficient knowledge to do the appropriate analysis. This drawback shows how, well before the analysis itself was carried out, the EA inventory was useful for the detection of the first requirement for the measuring system as the real-time monitoring of the temperatures of the input and output material flows of the system and of each process unit (sub-systems). The sampling frequency becomes an additional important requirement. The further definition of the complete set of measuring and monitoring devices has not been addressed in this work but will be object of future investigations.

\subsection{Hybrid EA-LCA}

A very useful method that allows any practitioner to overcome the problem of the real-time monitoring of temperatures is the Cumulative Exergy Demand (CExD) implemented on SimaPro v.9 software. SimaPro's CExD bases on the methodology introduced by Bösch et al. in 2006 [19] to quantify the life cycle exergy demand of a product or process.

The creation of broad life-cycle databases, such as Ecoinvent, provide a resource requirement for each unit process. With the aid of the software SimaPro, therefore, better CExD scores may be calculated that specifically reflect the exergy demand of a specific functional unit.

As regards the CExD carried out in the case study, the only metric is the amount of Exergy loss expressed in MJ. The evaluation is carried out through the life-cycle stages and all the starting assumptions are equivalent to those made for the LCA analysis.

The results are shown in Table 2. The following Figure 5 illustrates the overall impacts of one handle. The evaluation of the impacts for the CExD reported a total value of $27.60 \mathrm{MJ}$ per piece. The findings of the implementation of the CExD returned conclusions totally equivalent to those obtained with the LCA. Die casting aluminum results to be the most critic sub-process and the knob the most critical component of the

\begin{tabular}{|c|c|c|c|c|c|c|c|c|}
\hline & $\begin{array}{c}\text { Die casting } \\
\text { Zamak }\end{array}$ & $\begin{array}{l}\text { Die casting } \\
\text { Aluminum }\end{array}$ & $\begin{array}{c}\text { Plastic } \\
\text { molding }\end{array}$ & $\begin{array}{c}\text { Vibro- } \\
\text { tumbling }\end{array}$ & $\begin{array}{c}\text { Drilling and } \\
\text { threading }\end{array}$ & Painting & Assembly & Total \\
\hline Bushing & & & 0.3335 & & & & & 0.3335 \\
\hline Case & 5.5187 & & & 0.0532 & & 1.3155 & & 6.8874 \\
\hline Cover-case & 3.0028 & & & 0.0566 & & 1.4925 & & 4.5519 \\
\hline Knob & & 11.8752 & & & 0.0134 & 2.8025 & & 14.6911 \\
\hline Spindle & 0.7993 & & & 0.0421 & & & & 0.8414 \\
\hline Assembly & & & & & & & 0.2969 & 0.2969 \\
\hline Total & 9.3208 & 11.8752 & 0.3335 & 0.1519 & 0.0134 & 5.6105 & 0.2969 & 27.6023 \\
\hline
\end{tabular}
handle.

Table 2. LCA impact assessment by CExD all expressed in MJ

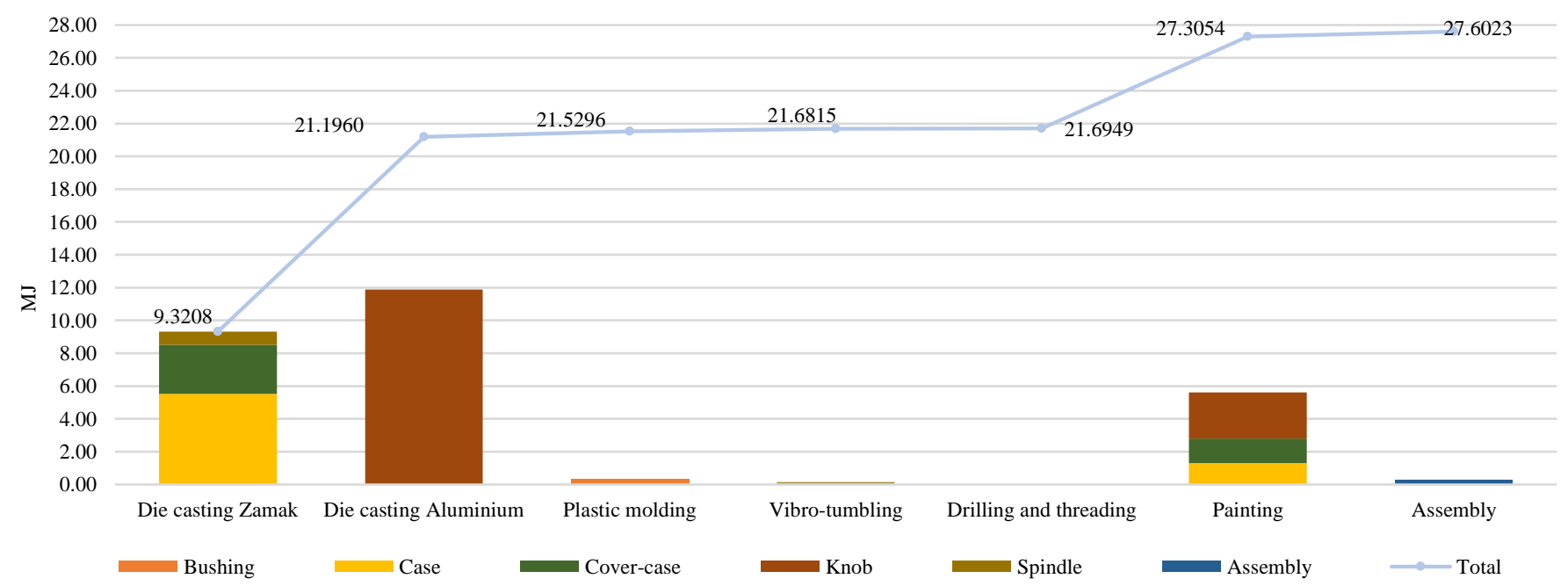

Figure 5. CExD: cumulative impact of each handle component related to the sub-process and vice-versa, in MJ. 


\section{CONCLUSIONS}

The models based on thermodynamic analyses, hence based on discrete variables, represent an innovative and interesting strategy for maximizing the sustainability of the manufacturing system performances facilitating the management of new smart manufacturing processes, thus driving the practitioners employing a suitable sensing system and information structure for a real-time monitoring, hence couple model-based approaches with data-driven ones and gather a comprehensive knowledge up until the implementation of a predictive manufacturing system. Datadriven approaches allow to analyze parameters within different fields, e.g. product, process and logistics, and enable the extrapolation of forms of cause-effect interactions that traditional methodologies (i.e. statistical models, physical models) cannot identify on their own. In this way, quality issues may also be defined and managed along with sustainability concerns.

Sensing systems for real-time state monitoring of dynamic manufacturing processes can be a framework for developing and testing new business models in the context of I4.0, as this automatically led to improved energy and technological performance, resulting in a reduction of consumption and maintenance and thus to several economic advantages.

\section{REFERENCES}

[1] Chiarello, F., Trivelli, L., Bonaccorsi, A., Fantoni, G. (2018). Extracting and mapping industry 4.0 technologies using Wikipedia. Computers in Industry, 100: 244-257. https://doi.org/10.1016/j.compind.2018.04.006

[2] Tay, S.I., Malaysia, T.H.O., Raja, P., Pahat, B., Hamid, N.A.A., Ahmad, A.N.A. (2018). An Overview of Industry 4.0: Definition, Components, and Government Initiatives. Jour of Adv Research in Dynamical \& Control Systems, 10(14): 1379-1387.

[3] Hermann, M., Pentek, T., Otto, B. (2015). Design Principles for Industrie 4.0 Scenarios: A Literature Review. https://doi.org/10.13140/RG.2.2.29269.22248

[4] Markley, M.J., Davis, L. (2007). Exploring future competitive advantage through sustainable supply chains. International Journal of Physical Distribution \& Logistics Management, 37(9): 763-774. https://doi.org/10.1108/09600030710840859

[5] Kiel, D., Müller, J.M., Arnold, C., Voigt, K.I. (2017). Sustainable industrial value creation: Benefits and challenges of industry 4.0. International Journal of Innovation Management, 21(8): 1740015. https://doi.org/10.1142/S1363919617400151

[6] Stock, T., Seliger, G. (2016). Opportunities of sustainable manufacturing in industry 4.0. Procedia CIRP, 40: 536-541. https://doi.org/10.1016/j.procir.2016.01.129

[7] Ruppert, T., Jaskó, S., Holczinger, T., Abonyi, J. (2018). Enabling technologies for operator 4.0: A Survey. Applied $\quad$ Sciences, $\quad 8(9)$ : 1650. https://doi.org/10.3390/app8091650

[8] Skliros, C., Esperon Miguez, M., Fakhre, A., Jennions, I. (2018). A review of model based and data driven methods targeting hardware systems diagnostics. Diagnostyka, 20(1): 3-21. https://doi.org/10.29354/diag/99603

[9] UNI EN ISO 14040, http://store.uni.com/catalogo/index.php/uni-en-iso14040-2006.html, accessed Feb. 05, 2019.

[10] UNI EN ISO 14044,

http://www.iso.org/cms/render/live/en/sites/isoorg/conte nts/data/standard/03/84/38498.html, accessed Oct. 21, 2019.

[11] Selicati, V., Cardinale, N., Dassisti, M. (2020). Evaluation of the sustainability of energy retrofit interventions on the historical heritage: A case study in the city of Matera, Italy. International Journal of Heat and Technology, 38(1): $\quad$ 17-27. https://doi.org/10.18280/ijht.380103

[12] Dincer, I., Bicer, Y. (2018). 1.27 life cycle assessment of energy. In Comprehensive Energy Systems, 1042-1084. https://doi.org/10.1016/B978-0-12-809597-3.00134-6

[13] Bakshi, B.R., Gutowski, T., Sekulic, D. (2011). Thermodynamics and the Destruction of Resources. Cambridge University Press. www.cambrige.org/9780521884556

[14] Moya, C., Domínguez, R., Van Langenhove, H., Herrero, S., Gil, P., Ledón, C., Dewulf, J. (2013). Exergetic analysis in cane sugar production in combination with Life Cycle Assessment. Journal of Cleaner Production, 59: 43-50. https://doi.org/10.1016/j.jclepro.2013.06.028

[15] Romero, J.C., Linares, P. (2014). Exergy as a global energy sustainability indicator. A review of the state of the art. Renewable and Sustainable Energy Reviews, 33: 427-442. https://doi.org/10.1016/j.rser.2014.02.012

[16] Pati, D.S.N., Pahuja, A., Selvarajan, M. (2009). Integration of Exergy with LCA For Sustainability. 11th NCB International Seminar, National Council for Cement and Building Material, Ballabgarh, 11.

[17] Portha, J.F., Louret, S., Pons, M.N., Jaubert, J.N. (2010). Estimation of the environmental impact of a petrochemical process using coupled LCA and exergy analysis. Resources, Conservation and Recycling, 54(5): 291-298.

https://doi.org/10.1016/j.resconrec.2009.09.009

[18] Cornelissen, R.L. (1997). Thermodynamics and sustainable development: The use of exergy analysis and the reduction of irreversibility.

[19] Bösch, M.E., Hellweg, S., Huijbregts, M.A.J., Frischknecht, R. (2007). Applying cumulative exergy demand (CExD) indicators to the ecoinvent database. The International Journal of Life Cycle Assessment, 12(3): 181-190. https://doi.org/10.1065/lca2006.11.282

[20] Meyer, L., Tsatsaronis, G., Buchgeister, J., Schebek, L. (2008). Exergoenvironmental analysis for evaluation of the environmental impact of energy conversion systems. Energy, 34(1): 75-89. https://doi.org/10.1016/j.energy.2008.07.018

\section{NOMENCLATURE}

$\begin{array}{ll}\text { Ex } & \text { exergy flow rate, } \mathrm{J} . \mathrm{s}^{-1} \\ \mathrm{H} & \text { enthalpy flow rate, } \mathrm{J} \cdot \mathrm{s}^{-1} \\ \mathrm{~m} & \text { mass flow rate, } \mathrm{kg} . \mathrm{s}^{-1} \\ \mathrm{Q} & \text { heat transfer flow rate, } \mathrm{J} . \mathrm{s}^{-1} \\ \mathrm{~T} & \text { temperature, } \mathrm{K} \\ \mathrm{W} & \text { workflow rate, } \mathrm{J} . \mathrm{s}^{-1}\end{array}$




\section{Greek symbols}

$\eta \quad$ exergetic efficiency, dimensionless

\section{Subscripts and superscripts}

0 dead state

c number of total enthalpy flows

d number of total workflows e equilibrium

g general

i state point at the inlet of sub-system

$\mathrm{k} \quad$ number of total mass flows

loss flow rate loss during the sub-processes

n net use

o state point at the outlet of sub-system

$\mathrm{p}$ number of total heat transfer flows 